\title{
INVESTIGATION OF NANOPARTICLES PRESENCE IN SPHEROIDIZED POWDER OF HEAT- RESISTANT ALLOY ON THE MICROSTRUCTURE AND PROPERTIES MANUFACTURED BY DIRECTED ENERGY DEPOSITION
}

\author{
Dmitriy MASAYLO, Sergey IGOSHIN, Nikolay RAZUMOV, Alexey ORLOV, Ivan GONCHAROV, \\ Evgeniy GYULIKHANDANOV, Anatoliy POPOVICH
}

\begin{abstract}
${ }^{1}$ Peter the Great St. Petersburg Polytechnic University, St. Petersburg, Russian Federation, dmasaylo@gmail.com
\end{abstract}

https://doi.org/10.37904/metal.2019.840

\begin{abstract}
During the spheroidization process of the heat-resistant alloy powder 3X11H2B2MF nanoparticles appears on its surface which can lead the influence on the microstructure and mechanical properties when manufacturing the parts. The paper presents the results of the microstructure study and mechanical tests of the specimens manufactured by directed energy deposition technology from the heat-resistant alloy powder with and without nanoparticles the recommendation of the further usage of the powder material obtained by plasma spheroidization are given.
\end{abstract}

Keywords: Plasma spheroidized, nanoparticles, heat-resistant alloy, directed energy deposition, additive technology

\section{INTRODUCTION}

Currently, designers are placing increasing requirements on the operating characteristics of products in order to increase their efficiency. Traditional methods for producing parts and components substantially completely exhausted from the standpoint of geometric complexity of designs (e.g. cooling channels, and lattice structures, etc.). Therefore, many large companies (GE, Boing, etc.) are actively implementing additive technologies into their production processes [1-4]. It is also associated with high mechanical and operating characteristics of products obtained by methods of layer-by-layer synthesis. The raw materials used are spherical metal powders obtained by atomization (water, gas, plasma) from the melt.

The market for raw powder materials offers a narrow range of alloys for additive technologies. Due to this the method of plasma spheroidization is gaining increasing popularity, which allows producing powders of spherical form from almost any alloy $[5,6]$. It is also possible to use secondary raw materials (chips) and mechanically alloyed powder compositions.

In the process of plasma spheroidization, nanoparticles are formed on the surface of the powder, which can affect the structure and mechanical characteristics of the products. The study of the effect of nanoparticles on the structure and mechanical properties using the example of the 3X11H2B2MF alloy was the aim of this work.

\section{MATERIALS AND METHODS}

Spheroidized powder of heat-resistant steel 3X11H2B2MF obtained from secondary raw materials (chips) was used as the initial powder material (Figure 1).

The process of obtaining powder took place in several stages:

- $\quad$ Grinding chips in the mill, or in attritor;

- $\quad$ Sieving powder;

- $\quad$ Spheroidization of powder in a stream of high-frequency plasma. 


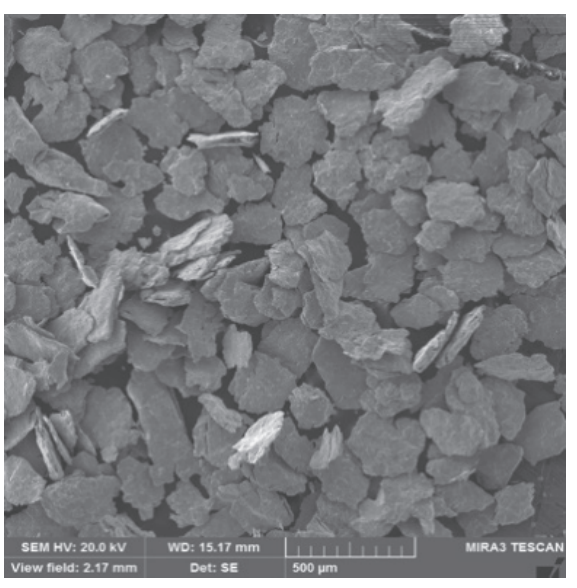

Figure 1 Powder heat-resistant alloy 3X11H2B2MF before (a) and after (b) spheroidization

The powder was classified to 71-100 $\mu \mathrm{m}$ and spherodized in the Tekna TEK-15 plant with ICP plasma torch power $15 \mathrm{~kW}$, feeding rate $30 \mathrm{~g} / \mathrm{min}$. Getting into the plasma jet, small particles evaporated with subsequent condensation on the walls of the bunker and other spheroidized particles. Table 1 shows the chemical compositions of the powders before and after spheroidization.

Table 1 The chemical composition in mass \% of the initial powder before and after spheroidization

\begin{tabular}{|c|c|c|c|c|c|c|c|c|}
\hline Specimen & $\mathbf{S i}$ & $\mathbf{V}$ & $\mathbf{C r}$ & $\mathbf{M n}$ & $\mathbf{F e}$ & $\mathbf{N i}$ & $\mathbf{M o}$ & $\mathbf{W}$ \\
\hline GOST 5632-72 & $\leq 0.6$ & $0.18-0.30$ & $10.5-12$ & $\leq 0.6$ & Balance & $1.5-1.8$ & $0.35-0.5$ & $1.6-2$ \\
\hline Before spheroidization & 0.38 & 0.26 & 11.80 & 0.35 & Balance & 1.53 & 0.47 & 2.05 \\
\hline After spheroidization & 0.39 & 0.27 & 10.90 & 0.25 & Balance & 1.52 & 0.48 & 2.0 \\
\hline
\end{tabular}

To remove nanoparticles from the surface, the powder was placed in a stream of gas, followed by the introduction of a gas-powder mixture into a cyclone. Due to the collision of powder particles with each other, as well as against the walls of the cyclone, the nanoscale particles were separated from the surface and ejected by the gas flow outside the volume of the cyclone. Powder without nanoparticles settled at the bottom. Figure 2 shows photographs of powder with and without nanoparticles.

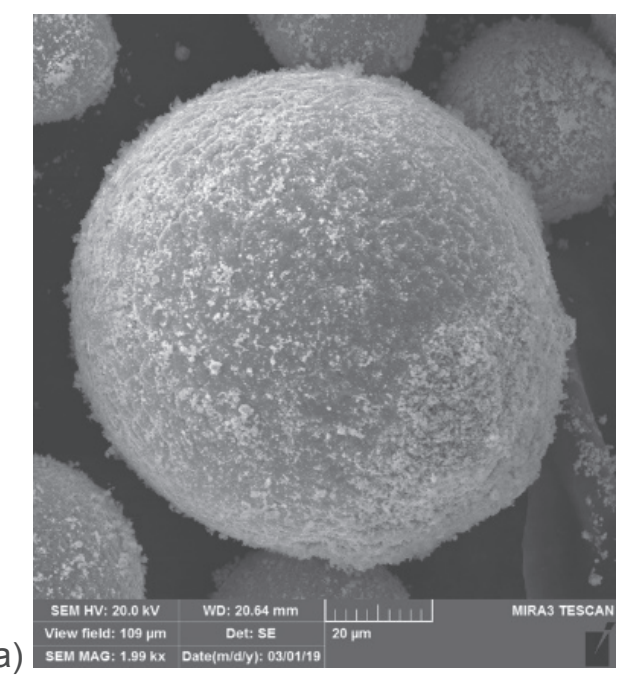

Figure 2 Photographs of a powder of a heat-resistant alloy 3X11H2B2MF with nanoparticles (a) and without them (b) 
Production of specimens was carried out on the DED unit (Figure 3 a). Schematically, the process is shown in Figure 3 b [11].

a)

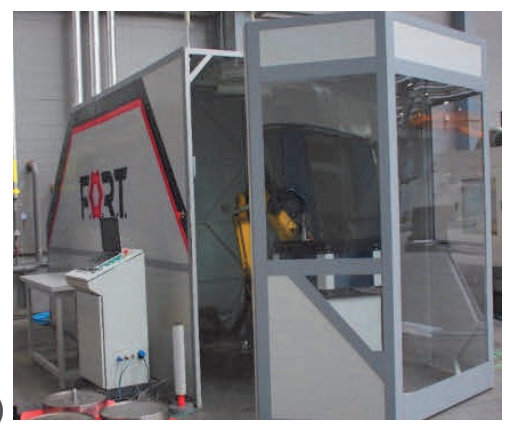

b)

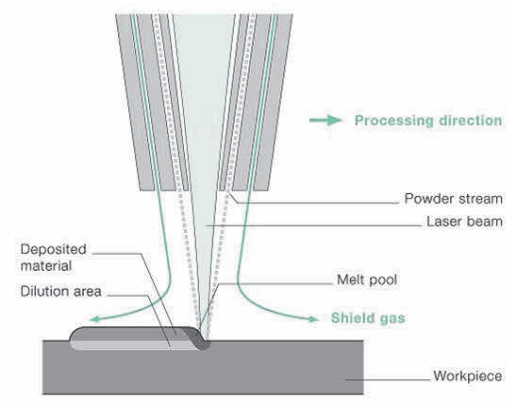

Figure 3 DED unit (a) and process sheme (b)

To investigate the structure metallographic specimens were prepared in two directions, parallel and perpendicular to the substrate for each of the powders (with and without nanoparticles). Mechanical characteristics were measured on a Zwick Roell universal tensile testing machine, and hardness testing on a Zwick Roell ZHU universal hardness tester.

\section{RESULTS AND DISCUSSIONS}

On the DED unit, single-pass walls were made for each of the powders (with and without nanoparticles) in the same mode: laser power $1000 \mathrm{~W}$, traverse speed of the manipulator $10 \mathrm{~mm} / \mathrm{sec}$ (Figure 4).

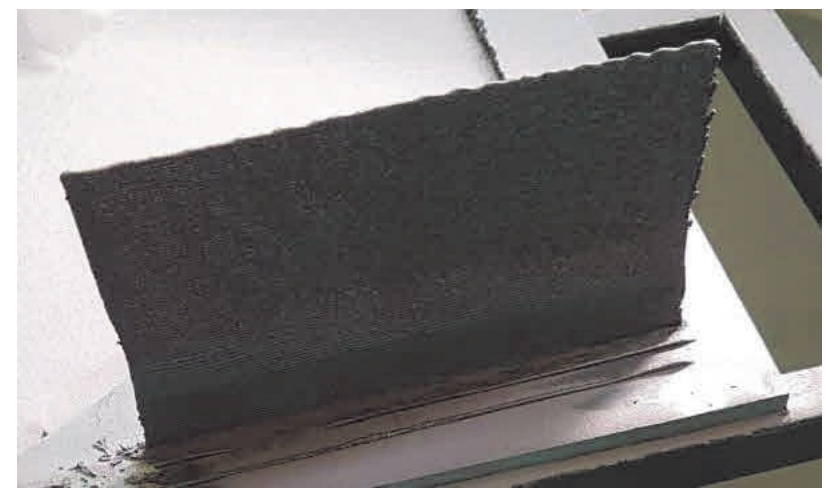

Figure 4 Single-pass wall of 3X11H2B2MF heat resistant alloy powder

Then, specimens obtained from powders with and without nanoparticles were sawn in two directions, pressed and etched in chloroazotic acid solution. Figure $\mathbf{5}$ shows photographs of the microstructure at lower magnification.

On the presented images it can be seen that the structure of the fabricated specimens using spheroidized powders from the $3 \mathrm{X} 11 \mathrm{H} 2 \mathrm{~B} 2 \mathrm{MF}$ alloy consists of tempered martensite. When building-up, initially the formation of acicular precipitates of the martensitic phase occurred. In the process of growing the subsequent layers of material, the underlying areas of the specimen were heated, which led to the release of martensite, which resulted in a partial disintegration of the martensitic phase into a ferritic-carbide mixture while maintaining the needle morphology of the precipitates and the orientation angle between them. This is also evidenced by blurred grain boundaries. The presence of darker areas along the boundaries of the needle-like precipitates indicates the formation of epsilon-carbides as a result of tempering. Fundamental differences in the structure when using powders with nanoparticles and without them is not observed. 
a)

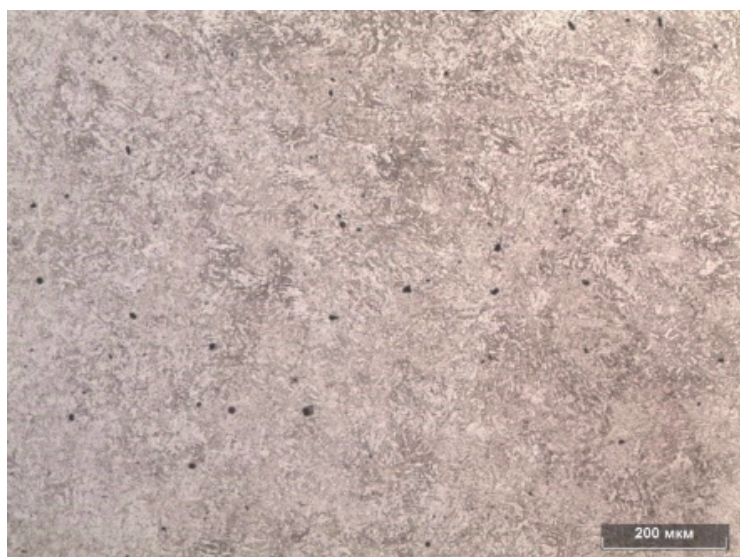

c)

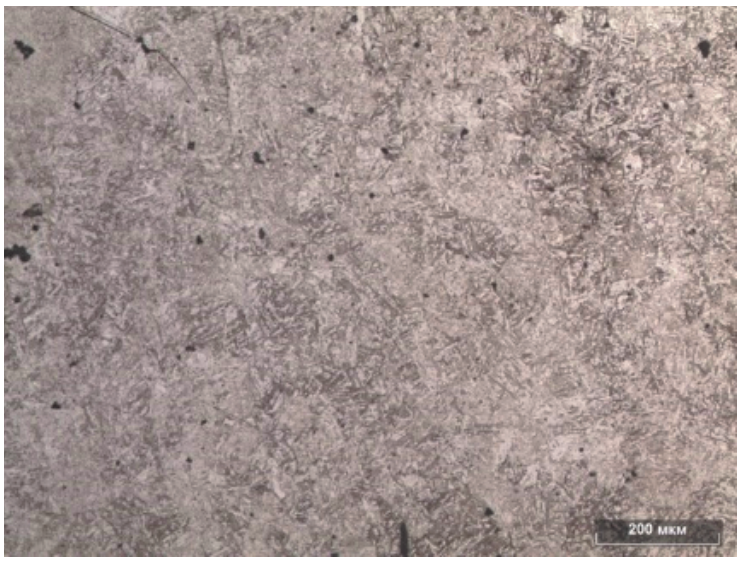

b)

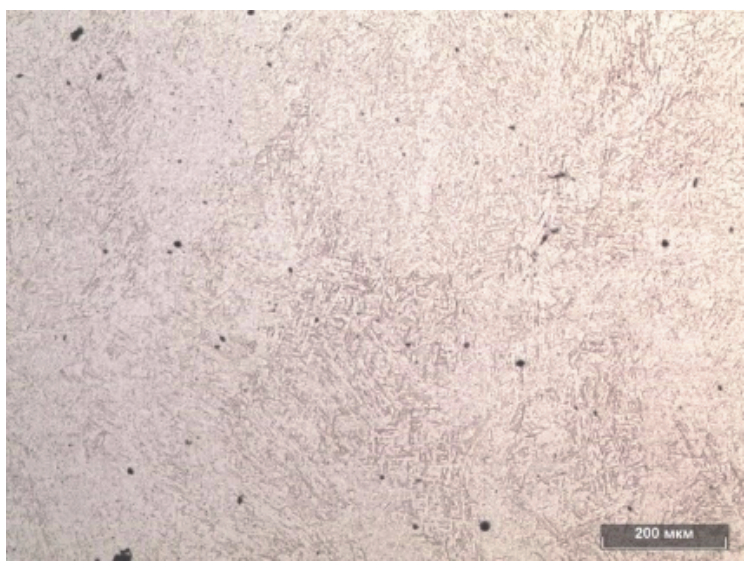

d)

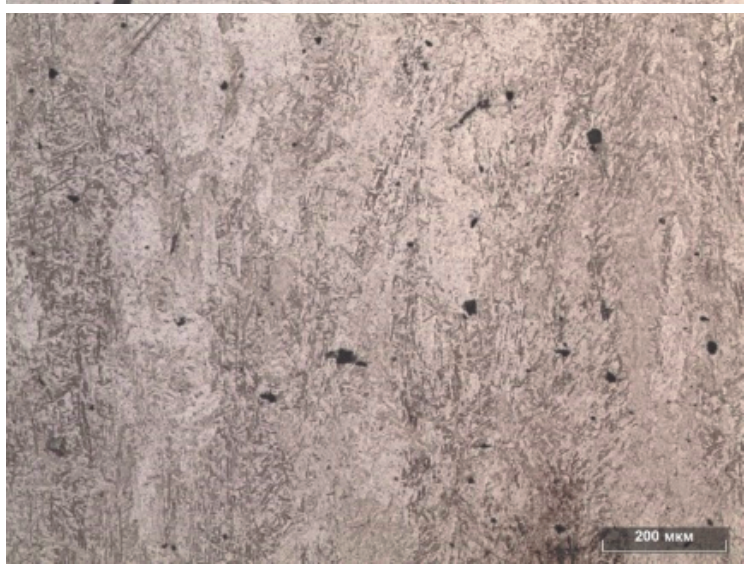

Figure 5 Photos of the microstructure of the specimens, where: a - with nanoparticles parallel to the substrate; $b$ - with nanoparticles perpendicular to the substrate; $c$ - no nanoparticles parallel to the substrate; $d$ - without nanoparticles perpendicular to the substrate

Table 2 presents the results of measuring the hardness of the specimens.

Table 2 Specimen hardness measurement results

\begin{tabular}{|c|c|c|c|c|}
\hline \multirow{2}{*}{ Specimen } & \multicolumn{2}{|c|}{ With nanoparticles } & \multicolumn{2}{c|}{ Without nanoparticles } \\
\cline { 2 - 5 } & $\begin{array}{c}\text { Parallel to the } \\
\text { substrate } \\
\text { (HV) }\end{array}$ & $\begin{array}{c}\text { Perpendicular to the } \\
\text { substrate } \\
\text { (HV) }\end{array}$ & $\begin{array}{c}\text { Parallel to the } \\
\text { substrate } \\
\text { (HV) }\end{array}$ & $\begin{array}{c}\text { Perpendicular to the } \\
\text { substrate } \\
\text { (HV) }\end{array}$ \\
\hline 1 & 43.5 & 44 & 40 & 37.1 \\
\hline 2 & 45.7 & 44.2 & 39.7 & 37.5 \\
\hline 3 & 44.9 & 44.4 & 39.8 & 38.1 \\
\hline Average & 44.7 & 44.2 & 39.8 & 37.6 \\
\hline
\end{tabular}

The results of hardness measurements show that the hardness of specimens with nanoparticles is slightly higher (about $10 \%$ ) than specimens without nanoparticles. Perhaps this is due to the fact that the specimens were cut at different heights. The closer to the substrate, the longer the time of thermal influence, and hence the lower values of hardness.

At the next research stage, flat tensile specimens according to GOST 1497-84 were manufactured in two directions: parallel and perpendicular to the substrate made of powder with and without nano particles. Figure 6 shows the stress-strain curves, and Table 3 shows the test results. 
a)
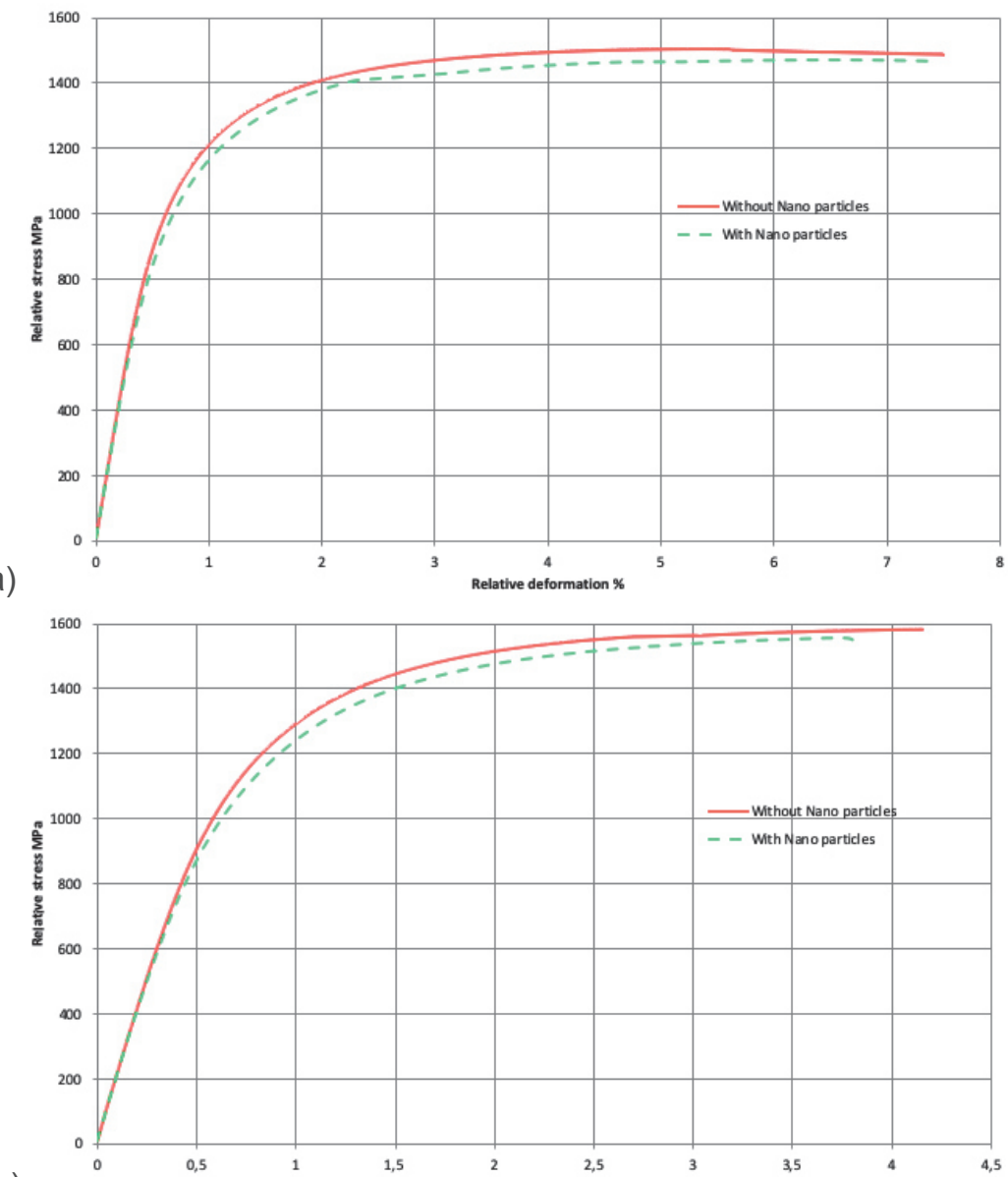

b)

Figure 6 Specimen stress-strain curves, where a - parallel to the substrate, b - perpendicular to the substrate

Table 3 Tensile test results

\begin{tabular}{|c|c|c|c|c|}
\hline \multicolumn{2}{|c|}{ Specimen } & $\begin{array}{c}\mathbf{R}_{\text {p0.2 }} \\
(\mathbf{M P a})\end{array}$ & $\begin{array}{c}\mathbf{R}_{\mathbf{m}} \\
(\mathbf{M P a})\end{array}$ & $\begin{array}{c}\text { Elongation } \\
(\%)\end{array}$ \\
\hline \multirow{2}{*}{$\begin{array}{c}\text { Parallel to the } \\
\text { substrate }\end{array}$} & $\begin{array}{c}\text { Without nano } \\
\text { particles }\end{array}$ & $1021 \pm 25$ & $1505 \pm 25$ & $5 . \pm 0.7$ \\
\cline { 2 - 5 } & With nano particles & $998 \pm 25$ & $1480 \pm 25$ & $4.8 \pm 0.7$ \\
\hline \multirow{2}{*}{$\begin{array}{c}\text { Perpendicular to } \\
\text { the substrate }\end{array}$} & $\begin{array}{c}\text { Without nano } \\
\text { particles }\end{array}$ & $1095 \pm 25$ & $1577 \pm 25$ & $2.9 \pm 0.7$ \\
\cline { 2 - 5 } & With nano particles & $1077 \pm 25$ & $1557 \pm 25$ & $2.4 \pm 0.7$ \\
\hline
\end{tabular}

Analysis of the results shows that anisotropy of properties is observed depending on the orientation of the sample. This is due to the direction of grain growth - to the substrate. It is established that nanoparticles have almost no effect on the strength characteristics. The values of the test results lie in confidence intervals. This is due to the fact that the chemical composition of the nanoparticles is identical to the chemical composition of the main powder. In the process of forming a continuous sample, the powder is completely melted both with and without nanoparticles.

Thus, the powder with nanoparticles has practically no effect on the properties of the products. Therefore, the removal of nanoparticles from the surface of the powders is not advisable. 


\section{CONCLUSIONS}

In this paper, we studied the effect of nanoparticles formed during the spheroidization of a powder on the structure and mechanical properties. It was established that the structure of the samples is tempered martensite with the release of epsilon-carbides along the boundaries. Mechanical tests have shown that anisotropy of properties is observed depending on the direction of the specimen (either parallel or perpendicular to the substrate). Specimens of powders with nanoparticles and without show almost identical results, thus their removal is not advisable.

\section{REFERENCES}

[1] Lyons, B. Additive manufacturing in aerospace: Examples and research outlook. The Bridge. 2014. vol. 44. no. 3, pp. 182-187.

[2] URIONDO, A., ESPERON-MIGUEZ, M. and PERINPANAYAGAM, S. The present and future of additive manufacturing in the aerospace sector: A review of important aspects. Journal of Aerospace Engineering. 2015. vol. 229, no. 11, pp. 2132-2147.

[3] HUANG, R. Energy and emissions saving potential of additive manufacturing: the case of lightweight aircraft components. Journal of Cleaner Production. 2016. vol. 135, pp. 1559-1570.

[4] WONG, K. V. and HERNANDEZ, A. A review of additive manufacturing. Mechanical Engineering. 2012. vol. 4, no. 8, pp. 1-10.

[5] RAZUMOV, N.G., POPOVICH, A.A. and GRIGOR'EV, A.V. Morphology of high-strength heat-resistant steel powder for machines for additive production from shavings. Metal Science and Heat Treatment. 2019. vol. 60, no. 11- 12. pp. 710-714.

[6] JIANG, X. L. and BOULOS, M. Induction plasma spheroidization of tungsten and molybdenum powders. Transactions of Nonferrous Metals Society of China. 2006. vol. 16, no. 1, pp 13-17. 